\title{
Performing illness and health: the humanistic value of cancer narratives
}

\author{
Maheshvari Naidu \\ School of Social Sciences (Anthropology), University of KwaZulu-Natal, Private Bag X5400I, Durban, South Africa \\ naiduu@ukzn.ac.za
}

\begin{abstract}
Cancer is a potent example of a disease that grips and plays out on the body in ways that are both visceral and visual. This paper explores issues of disease and disorder, functioning and malfunctioning in bodies marked by cancer and a sense of nonbelonging. By working through the heuristic device of 'narrative', the paper argues for the humanistic value and currency of the personal (subjective) illness narrative in social science scholarship in being able to convey to audiences the emotional and existential complexities of cancer, beyond the merely medical. The paper, by drawing on ethnographic narratives of a small group of women with cancer and their inscriptive treatment practices, probes the shifting and constructed concepts of a socalled 'healthy' body and 'ill' body as experienced by the women, and attempts to show that a recognition of these experiences of the physical body is potentially able to contribute to shaping more compassionate, person-centred health care models of illness and healing.
\end{abstract}

Key words: Women, cancer narratives, disease, body, illness, death, dying

\section{Introduction}

The grand design of the biomedical model reduces illness to a biological mechanism of cause and effect (see Wong and King 2008:58I), while the practice of medicine itself is broken down into smaller and smaller 'medical bytes' in the name of specialisations: the oncologists, the cardiologists, the radiologists, the surgeons and so on. These specialists and subspecialists all take care of different parts of the same body, while cancer itself impacts on the entire body and person. Allowing patients to share their stories about what is happening to them, in the context of their illness, encourages them to talk about themselves as 'selves' rather than just organs, even as they might be describing particular parts of their bodies and what is happening to their bodies. Narrative theory in turn privileges unvoiced and marginalized discourses (see Reissman 1993, Dale and Altschuler 1999; Daiute and Lightfoot 2004; Petraglia 2007) and considers alternative narratives to be part of the whole narrative structure. In the context of this study, the alternate narratives are the patients' sociological stories of 'bodies as selves' (as told by the patients) and their shifting embodiments of illness and health. These are the 'storied' records that offer an alternate picture of the 'patient' as person. They offer an alternate 'story' to the medical narratives or charted pathologies that are written into the women's medical records.

This paper' thus seeks to add to the discussion on the humanistic value of narratives in understanding cancer and the lived experiences of women with cancer. It further seeks to position these narratives within the larger cancer health care system. It is held that research that informs core functions of the cancer health care system and how it is received by the beneficiaries is critical and must reach across a very diverse population of care-givers; the physicians, the oncologists, the nurses, the radiologists, as well as the patients and their family members.
Qualitative research methods have long been used in the social sciences. However, the use of these methods in branches such as family medicine research is relatively new (see Karwalajtys et al. 20I0). Yet the politically structured and largely positivistic praxis of family medicine, oncology and nursing has much to gain in the kinds of humanistic and meaningful medical care they are able to offer to those who seek their help, from phenomenological insights gained in qualitative social science research with patients. For it is not merely the body-with-cancer that consults with the health care practitioners, but also the Self with-cancer-body. What patients have to share is thus vital. This is the point of insertion for this study.

There are, of course, multiple, fluid, and sometimes competing constructions of 'self' that often inhere in disciplinary borders. However, in the context of this study the 'body', following Waskul and van der Riet (2002:487), is taken as 'the empirical quintessence of the self', and 'embodiment' is taken to represent the personification and visible materialization of otherwise invisible qualities of personhood. The studies a priori assumption is that the body and experiences of embodiment are central to our sense of being and who we think we are and how we experience who we think we are.

\section{Methodology}

The female cancer patients in this study are approached through the 'body', in order to attempt to comprehend their understandings of what they felt was happening to them and the intimate spaces of their bodies. By asking questions about their bodies and listening and observing what they had to say, and how they said it, an understanding is assembled of how they come to see and perform themselves within the context of their diagnosis and their prescribed treatment regimes. I have dwelt at length on this methodology section for the simple reason that, given the sensitive nature of the study and

I. I would like to acknowledge and thank the two anonymous reviewers who raised important critical questions. Their comments and insights have helped sharpen the arguments in the paper. 
the often frail and fragile health of the participants, how one does such a study, is, on some levels, as important as the information that emerges from the study.

It thus bears noting that the methodology used here was in a sense stitched together differently from my other studies, many of which also involved working with narratives and narrative analysis. While serving as a part-time volunteer at a local hospice and after obtaining permission from the senior nursing sister in charge, I recorded notes containing details of patients, events, and my casual interactions with patients and staff. For the most part, however, the volunteering only indirectly related to data collection; it was important for me to offer some of my time to an organisation that I had personally witnessed playing a massive role in patients' lives and it proved a wonderfully organic way for me to establish rapport with the medical and nursing personnel and the wider network of support staff, as well as providing me with legitimate and informed access to patients and prospective participants.

The data in this study is drawn primarily from approximately thirty-nine personal one-on-one interviews with fifteen women. The sample group is small, as it is, understandably, a highly intimate and an intensely personal experience of illness and suffering that I was exploring, and it was not always feasible to identify and invite participants in the way a researcher normally would. A light hand was needed in the selection of participants; one that was mindful of the fact that not all women would want to share intimate details of their illnesses and their bodies, and that not all women would necessarily find such 'sharing' cathartic or helpful. The nursing sisters were invaluable in introducing me to women they felt would be comfortable enough to talk to me, and whom they thought might on some level benefit from talking about what was happening to them. As the Hospice nurses were already in a 'care relationship' with the women, and had their patients' interests as their priority, $I$ in turn was comfortable with the final core sample of participants who consented to talk to me.

While I spoke with many more women, these women are not formally included in the core sample. Given the nature of their illnesses, and the relationship that developed between them and myself, I did not think it appropriate to continue to include their narratives in the study. For even though these women had initially consented to participating in the research, the often fragile and delicately held together (and often failing) memory and emotional health made it clear that they did not always remember the details of my study. Put simply, these initial participants had forgotten what they had given consent to and forgotten that I was a researcher. They had begun to treat me as a friend and shared details of what might well be highly personal and confidential; what one friend might well tell another. Their narratives thus do not feature in the paper, but I am indebted for the insights gained from the time spent with them, in that it allowed me to listen more deeply to the women that I included in my core sample.

While cancer is indiscriminately fierce in its hold over both men and women, the study concerned itself only with the experiences of women ${ }^{2}$. Cancer is claimed to violate the body in three areas "where the greatest ambivalences are experienced: sexuality, reproduction and excretion" (Brown et al. 20I I: 283). For me, these dark spaces of ambivalence exert a more powerful bearing over women ${ }^{3}$, their bodies, and their sense of sexual and reproductive self. Within the context of cancer, it is also the palpable sense of a loss of privacy and surrender of 'female spaces', otherwise considered intensely intimate and normally shrouded from public 'gaze'. Additionally, my own gendered identity as female researcher further prompted me to work with women.

For the women in the final core group, I was careful to ensure that both the details of the study, and that that informed consent, was reiterated throughout the research period. This was important, given the nature of this research. Permission was also obtained from the patients' doctors and wider family in the case of three of the elder women, who appeared more fragile, and at times in visible pain or discomfort. Interviews and conversations were always rescheduled under these circumstances. The patients' ages ranged from thirty-one to sixty-seven. While most of the patients in my core group were terminally ill and on the hospice roster of weekly scheduled home visits, there were three others who were not (although they were also introduced to me by the hospice sisters). The interviews themselves were unstructured and non-standardized (Denzin 1989), conducted over eight months, and consciously asked broad and fluidly-constructed basic questions in an attempt to approximate an informal conversational structure that revolved around unrestricted open-ended discussions. All the interviews were conducted at the women's homes.

Two hospitals were also visited during this period. The nursing staff and doctors that I had struck up an acquaintance with were interviewed and there were opportunities for informal discussions with women in the consulting rooms. My entree here was facilitated by the fact that I frequently brought over hospice literature and material into these waiting rooms. This literature consisted of various publications on

2. Although this was not a direct line of inquiry for me in the context of this study, a number of studies in psychosocial oncology suggest that men and women cope differently with cancer. These studies claim that women express their emotions more readily than men do and that men rely more on their healthy spouses. Salander and Hamberg's (2005) article, entitled 'Gender Differences in Patients Written accounts about being Diagnosed with Cancer', found that the women (as opposed to the men in the cohort) wrote longer, wrote much more in personal terms and far more emotionally. Salander and Hamberg also reveal a concern with a gender bias in oncology. They claim that most studies on gender differences in health are conducted outside oncology, but that there is a growing body of research on gender aspects within biomedical oncology and psychosocial oncology (2005:685). Brown et al. (201 I:283), whose qualitative work was with women with gynae-cancers, acknowledge that the presence of abnormal cytology is inherently infused with significant meaning and socialised assumptions which are mirrored and echoed in the particular way gynaecological anatomy and functioning are bound up with notions of the feminine self.

3. Studies of women with breast cancer show how notions of sexuality and femininity are 'wrapped' and entangled around the anatomical breast, and all that the breast signifies in terms of popular culture and socialised notions of feminine beauty and attractiveness (see Van der Riet 1998 and Waskul and Van der Riet 2002). 
the nature of cancers and what patients can expect, as well as so-called 'autopathographies' written by cancer patients. They give some insight into current vernaculars and discourses surrounding detection, treatment, and cure in cancer communities, as well as allowing a window into highly intimate and very personal experiences of illness and suffering. None of the core participants were formally interviewed at the hospitals. Rather, the discussions with the nursing staff and medical practitioners helped construct both the epidemiological as well as the social face of cancer. The discussions with the nurses, especially, shed some light on how many of the women appeared to respond to and cope with the treatment regimes and bodily changes over the prescribed period of radiation. Thus, the time spent at the hospitals, together with that spent at the hospice, afforded observations that helped build an understanding of women entering the oncology departments for their treatment regimes. In many instances the same group of women were observed over a period of two months, as many usually came in at set times every day for their radiation or chemotherapy. Many women who had walked in independently at the beginning of their treatment would finish up their last fifth or sixth week in wheelchairs, as the daily regime took its toll on the body.

Many studies focus on single cancer pathologies and their patients, such as breast cancer, (Knopf-Newman 200I; Herndl 2006), gynae-cancer (Juraskova 2003; Markovic 2004) and so on. The women in the core group of this study, however, had different types of cancer, which included breast cancer, colorectal cancer, ovarian cancer, lung cancer, and renal cancer. Several of the participants had breast cancer. Lung cancer may appear less of an attack on the feminine 'self' in the context of femininity and a violation of intimate bodily space as compared to, say, colorectal or breast cancer. In reality the women's narratives all conveyed a loss of control over intimate and private bodily processes, whose control and 'sight' had to be surrendered to medical staff and or care givers. All the women had been diagnosed within the last two to four years. Two had had mastectomies and were in remission and all others were told that they had stage three or stage four cancers. Many suffered from secondary cancer and were dying. At the time of writing this paper, three had died, and many were close to death.

\section{Of blood, hair and skin}

A patient, long before [s] he becomes the subject of medical scrutiny, is, at first, simply a storyteller, a narrator of suffering, a traveller who has visited the kingdom of the ill (Mukherjee 2010:46).

Thirty-nine-year-old Rose ${ }^{4}$ tells me that her very first encounter with cancer was when she began to lightly bleed erratically over the course of several weeks and she knew that it could not be her menstrual cycle. She says she found it odd and curious and was not overly perturbed, as there was no pain.

I was okay ... you know ... no pain ... nothing overly uncomfortable, except for the obvious. I suppose I should have been alerted by my GP telling me that I should just have it checked out with a specialist surgeon. I remember sitting and waiting for my turn at the surgeon and moving up, chair by chair, getting closer to my turn. It's funny what you remember when you turn and look back. He asked me a lot of questions. He was quietly spoken... he seemed especially interested in how long I had been bleeding, the colour of the blood, how much blood there was ... you know, things like that. I remember thinking, I have never thought so much about blood since I first entered puberty ... He gave me an examination ... it was quick ... it seemed that the examination merely confirmed what he knew ... he told me he was sorry but it was cancer ... the rest of it ... sending me to blood tests... More blood I thought ... and scheduling ultra scan and colonoscopy ... all of that washed over me ... so that's what that blood was ... Who would have guessed ...?

For Rose, the blood that she now saw meant not only something dramatically different in terms of the blood itself, but it was also a radical reordering of how she had to see herself. For her it was also, in a sense, the blood that she had to be visually confronted with as the nurse extracted and filled it into vials to be analysed further for cancer cell markers. She tells me that she began to see herself as 'marked' and 'bloodied'. Rose's biopsy confirmed a diagnosis of colorectal cancer, which presents with pathological rectal bleeding. Rose continues to share her feeling that she began to resent the blood that she now saw; sharing that it began to frighten her. Every visit to the bathroom became a dreaded visit, and every discernible change in colour of the blood she saw was terrifying. It was, she said, as if the deepening shade sealed her fate, much like her narration of moving up, 'chair by chair' in the waiting room, until it was her turn with the physician. Rose, who was in the advertising industry, was not yet forty and said she had thought of herself as being in the prime of her life, with successful and high-achieving children and a loving partner. She had also received a hard-won promotion two years earlier. However, according to what she shared, there was scant time to enjoy this corporate climb. Her diagnosis had been swift, and because she was on medical aid, the treatment schedule of what is termed neoadjuvant therapy (given prior to surgery) was equally swift. She says she barely had time to think before she had begun her first refraction of radiation. However, the regime of combined therapy of chemo and radiation had proved difficult for Rose to bear and her surgery had to be postponed twice. Although fairly young, her family history of diabetes (and her daily intake of metformin and glycomin-blood glucose regulating medication), meant that her health had also been compromised in other ways. She says that she had twice gone into dangerously low blood sugar levels and had become dangerously anaemic and needed blood transfusions. The radiation and chemotherapy had compromised her health to the extent that treatment had to be halted, as it was killing her, she says with a strained smile. In the meantime, the cancer had metastasized to her liver and lungs. "Or maybe it was always there waiting for us to look", she adds limply. Although Rose was

4. Out of respect for the women, pseudonyms are used throughout. 
gathering her strength to attempt the surgery, telling me that she had two young children, it seemed that she felt that she was fighting a losing battle. And even though she says her family constantly reminded her about being young and strong and having the children to think of, in many ways she felt "dead already".

Her final words the last time we spoke ${ }^{5}$ were about her children. They were also about her.

I don't know which is killing me faster, the cancer or the treatment ... the doctors are nice, but to them, we just another one with cancer ... It's not that I don't believe in a God anymore ... I mean I still want my children to go to Church ... I still want God to take care of my angels ... but I don't have the energy anymore to pray for myself ... what's the point ... I can barely feel anything anymore ... we get all this pain medication so we don't feel the pain, but what the doctors don't realise is that then we can't feel much of anything anymore ...

Although the research sample was small, there was some diversity in terms of race (the women were Caucasian, Indian and African), educational background and socioeconomic status. The women also came from different religio-cultural backgrounds. These differences appeared, at times, to influence the manner in which some of the women understood death and bore their pain and suffering. However, the impression from their narratives (such as the one above from Rose) was that, at such an advanced stage in their cancer, and given the multiple medications they were on, there was very little space or time to enact their religious selves. In my first draft of the paper, I did not say much about how the women's religio-cultural backgrounds may have influenced their understanding of their illness, or their pain and suffering. This was deliberate. Yet, this is not to say that it was not important. Indeed, two of the women had had a highly religious upbringing and three appeared surrounded by a warm nexus of relatives who were religious adherents of two well known religious organisations. However, in questioning how their religious faith or cultural backgrounds may have affected how they approached their illness and diagnosis, it became clear that, for many, the heightened and perpetual levels of exhaustion and the 'flatness' (engendered by many of the pain medications) that they experienced, meant that it was more than enough to simply handle the day-to-day and moment-bymoment experience of what was happening to them. While journal accounts and autobiographies of cancer survivors often present stories where cultural backgrounds and personal religious beliefs have anchored them and helped them cope with the personal experiences of disease and disorder (see Wong and King 2008), this was not the case with the women in my study. It is not that they lacked agency and religious faith as such, but that the particular terminal nature of their illness rendered them, on many levels, as profoundly disconnected, even from their core and cherished beliefs and faith.

For forty-year-old Mary, who knew herself to be in a high risk group because of her chain smoking, the blood she coughed up in her tissue was accompanied by an immediate feeling of tightness in her chest.

I thought, oh my God what is this? Smokers get reminded about cancer all the time, but no one in my family had it ... and we were all smokers, I can tell you. I was feeling a bit rotten and grotty as I had the flu ... a heavy chest cold, so I could have thought it was bronchitis, but I thought ... cancer ... and you know ... it was ... stage 4 ... the doctor told me ... how did it bypass stage one and two and three and get to stage four I thought ...

Mary's story here evokes the sense of pain that is clearly evident when seated across from her. Her sharing her bewilderment at how her cancer could transgress the early stages, and suddenly manifest at stage four was evocative of her pain and bewilderment at the way her life could transgress and flout the 'living part' and so rapidly progress to dying and death. In both Mary and Rose's stories there is the leitmotif of blood, the symbol of life, now cruelly inverted to mean death. Both of them, like several other women, speak about experiences of extreme embarrassment about bleeding in public, even on those occasions they knew that only they were aware of it. Rose talks about feeling like everybody could see her bleeding and says she would pray to control it. She says she felt "very lonely at those times"... like she "was all alone" even if she was "in a group of people", and that she was willing herself out of her body. Such stories of an abject body speak to an extreme kind of self-othering. An abject body is a "messy, polluted, sick, and damaged body", says Julie Kristeva. It causes experiences of "brutish suffering" (Kristeva 1982:2) in the form of disorder, powerlessness and pain. This is a state in which coherent and normative bodily boundaries erode and the self has little control over the leaking of blood, urine, faeces, vomit, bile, pus, and various other so-called hideous body fluids", the stuff we don't talk about in public or polite company (ibid). Both Rose and Mary's cultural backgrounds and personal grooming habits indicated that they had been fastidious about hygiene. They both spoke about deep feelings of dirt. However, they spoke about dirt in ways that transcended bodily dirt. It was dirt that they felt they could not wash off (be rid of), as it violated their coherent boundaries as women, especially in Rose's case, where there was rectal bleeding.

The abject body, because it may become unreliable or difficult to control, can compound the experience of alienation. These experiences also serve to create experiential and conceptual distance between the self and the body. Pamela van de Riet (2002: 495) talks about this as a kind of corporeal irruption which can alienate the self from the body. In these conditions, we can readily understand how the body becomes disconnected and alien in very personal ways. This kind of distancing was apparent with the women in this study as well. They did not want any leaking of this blood which, in their understanding, belonged inside the body. And once outside the body, Rose and Mary felt shame. It (the blood) was not theirs, and they wanted nothing to do with this 'thing' that had crossed a boundary meant to be impermeable. This

5. Rose chose to not continue the interviews thereafter. She gave me permission to use her 'story', but felt that it was too painful to meet with me again. 
is very much in the vein of what the classic work of Mary Douglas (1966) would define as a taboo and a boundary impeached.

Cynthia expressed a similar sentiment: "I began to hate the sight of my own blood ... I hate the sight of my own blood." The sentence, that began in the past tense ("I began to hate the sight of my own blood ..."), ends in the present ("I hate the sight of my own blood") and acts as a kind of selfsentencing. This seemed to be reinforced by some of her interactions with the medical practitioners and nursing staff. Cynthia, like some other women, indicated that although the medical staff were "not unkind as such", they felt that their attitude changed once their prognosis shifted to palliative or terminal: even the radiation and chemotherapy administered to them was administered merely as a short reprieve from their (terminal) sentence. This, according to Cynthia and others, is experienced in the way the women claim they were treated by the nurses as well. One may be tempted to perceive such comments as highly subjective and compounded by pain and frustration, but it is important to acknowledge such feelings. This shift in the perceived attitude of medical staff is also mirrored in the provincial policy regarding where one can get oncology treatment in KwaZulu-Natal. When a cancer patient in public health care is 'medically moved', or when their prognosis changes from 'curative' to 'palliative', the patient is moved as an outpatient at the Albert Luthuli Central Hospital oncology unit, to the oncology unit at Addington Hospital. This is because Albert Luthuli Central Hospital does not offer treatment to terminal cancer patients. Addington Hospital has a relatively new (2009) state-of-theart radiation unit and accepts patients for both radical radiation (radiation in preparation for surgery) as well as palliative radiation. However, the fact that Albert Luthuli does not offer palliative treatment, and that terminal patients are therefore sent to Addington, makes her prognosis patently obvious to the patient. Of course, this prognosis would also have been communicated by the oncologist. However, the change in hospitals and even the new 'treatment regime' serve as perpetual reminders of their terminal status. Several of the respondents spoke about their sense of feeling let down when the move from one hospital to the other meant that they then "had to see a different oncologist, who did not know (them)". Many claimed that the counselling was minimal, as the bulk of the visit was taken up with waiting (their turn) and then with the radiation or chemotherapy. Actual consultations with the oncologists were on a monthly or fortnightly basis.

Cynthia, one such patient who had been moved, speaks about how the system "betrayed" her. Cynthia goes on to share that even when she stopped bleeding, she was "still getting more ill". She was getting so ill in fact, that she needed transfusions. She tells me that she had always thought of herself "as a strong woman....the anchor" for her large extended Indian family. Cynthia says that she never thought that so much of her "identity" was about her body and the health of her body. She had simply "gotten on with life", which included (as is customary in many Indian households) taking care of her elderly mother-in-law and even her physically disabled brother-in-law. For women, who may or may not have previously conceived of the ways in which their bodies mark their identity, illness and health can present a compelling way for them to understand the limitations of their bodies. The beginning of a regime of chemotherapy demands initial baseline blood tests and then heralds cascading levels of side effects of the treatment, which further complicates a woman's relationship with her body, her gender, her sexuality, and her identity (Knopf-Newman 200I: 83). Gloria (whose treatment had also brought her to Addington Hospital) tells me that she has to steel herself to "take those damn blood tests".

You know the ones they make you take before you begin your chemotherapy and radiation ... so that they have a base line ... We have to give blood ... sometimes, they cannot find the vein and they have to try again and again ... you know how they do it ... so business-like sometimes. So we give blood and hope and hope that something changes. In the meantime the chemo changes me ... I feel ghastly, and like I'm not human ... I look different ... less human ... less a woman ... .

The loss of hair compels a different understanding of the way the body signifies gender, sexuality, and illness. One of the women, Julie, says:

You know, I could hardly look in the mirror anymore. The pain is one thing ... people can't always see that you know. But my bald head. You can't hide that under a scarf. People see the baldness even more if you put a scarf to cover up ... it's like losing a female part of you ... it's okay for men ... but for women to be bald ... you just know its cancer...

Hair loss is particularly difficult for women. From what the women shared, even those who, prior to their illness had rarely paid much attention to their hairstyles and as busy mothers wore their hair pulled back in a simple pony-tail, were heartbroken by the sight of their balding scalps. Julie was a black African woman in her early sixties. Her story speaks to a kind of hypervisibility (see Naidu 2009) in an attempt to make herself invisible with the scarf. While she tells me that she had often worn a scarf in the recent past, and had regularly worn one when she worked "as a housemaid" in her teenage years, she found it difficult to wear one now. She told me that the scarf "made it known to everyone", claiming that this attempt at concealment visibly and visually heightened the hair loss and "announced it to all".

For many it is difficult to put into words what it means to live in a hairless body. Julie goes on:

Sometimes, you become like someone else. You feel out of your body ... the tumour has taken over the body. It is not just where the scan shows it ... it is everywhere, controlling everything you do.

Julie also shares that, over and above the grief over her hair loss, she suffered the embarrassment of being unable to style what little was left of her hair: she could not lift her arms to comb through her hair. Julie's story makes clear that by being a patient one allows others to assume control over significant portions of the body, its treatment, maintenance and care. Patients must relinquish some control over the body when accepting treatment. By adopting the language and the lexicon of medicine, patients may speak of their bodies as some- 
thing apart from them, distant objects described in terms that do not directly evoke any personal connection (Waskul and van der Riet 2002:496). Julie also notes that having cancer in the South African black community carries with it the stigma of the "other disease" (HIV/AIDS).

You know, some of my relatives saw me losing weight and vomiting and all that, and they did not believe it is cancer, they kept whispering that it must be AIDS. That also forced me to try and run away from my own body. You see, even though I did not know people with cancer, I knew about AIDS ... some in my family had died from this and I know what it looks like ... and how you die ... So if these people said I looked like I also had AIDS ... it meant I was going to die ...

At this point she trails off and begins sobbing quietly without completing her sentence.

In later interviews I am able to gently ask what she meant by wanting to "run away from (her) own body". Julie struggles to find the right words and tells me that she wants to "not be how I am now", and to "go back" to the way she was, or "force this weak body to eat and keep the food down!”

Blood, hair and skin thus form powerful themes around which the ethnographic narratives began to arrange themselves as the treatment regime began to impact on these bodily artefacts. In the case of the women with breast cancer, the cancer was something they discovered by the simple act of touching their skin. One woman tells me that the cancer tumour was discovered from the act of touching her skin while she was doing her regular monthly check and palpating her breast. For the others the tumour was discovered while they were going about their regular routines: bathing, towelling or applying lotion. Such activities, which had previously been seen simply as mundane activities ("hardly momentous events", as Shirley puts it), suddenly took on new meaning. Joan explains:

I immediately went to the mirror and tried to imagine myself without my breast. I even tried to squish one down so that I could see what it would look like. It was horrible, what kind of woman would I look like?

Don't get me wrong. I wanted to live. I am not vain. But it was my body. I could not bear it ... and when the oncologist and surgeon confirmed ... I started to change the way I saw myself. I know I should have been thinking ... yes, get the cancer out ... but I kept thinking: leave my breast on ...

The women with breast cancer all shared their initial terror of losing "that part" of themselves, as they put it. There is a particular kind of dread in women that appears to be evoked by even the mention of breast cancer, notwithstanding the significant success rates of treatment. Breasts are, in many instances, (perhaps much to the mortification of some feminists), deeply entangled with notions of both sexuality and femininity.

In many ways, the body is experienced through the skin: what we can and cannot put on our skin, and what we can and cannot wear and feel against our skin. A very emaciated Shirley, who, for the most part, had started to live (out of sheer convenience) in a nightgown, shares how sad she is that she will never be able to feel one of her many beautiful saris wrapped around her body again. Shirley is a Hindu and had loved her Indian dress and cultural jewellery. Her deep and constant neuropathic pain (a common side effect in chemotherapy), which she feels in the tips of all her fingers, means that she can barely touch anything, not even her own body. In contrast to acute pain, which usually signals a temporary problem, chronic cancer pain is, as described by many of the patients, doggedly persistent. Shirley says because of the pain she has been forced to endure, she has suffered the loss of her lifelong sense of privacy about her body - a body which is now seen and touched by all those who provide her care. Like Shirley, Loren also felt deeply humiliated that someone else had even to apply the facial cream onto her face. She spoke about not feeling like she was in her body, of being made numb and feeling a perpetual sense of 'flatness', brought on by increasingly high doses of pain medication. The medication, she says, while working at the level of distancing her from the pain, also works at distancing her from herself. Even when she touches her body, she "cannot feel (her)self".

'Weeping' is another skin condition, and is a term familiar to radiologists. It refers to the collection of fluid under the superficial epidermis that pools and collects under the skin. It starts off as a tiny fluid-filled bubble sac and grows and grows until it engulfs the entire leg and as it bursts and all the fluid falls or 'weeps down', it pulls away the entire skin, leaving raw skin underneath on legs grotesquely swollen. This action gives the characteristic name for the condition. The feet are, in turn, unable to be placed in shoes or even rested on the floor. When I met Leanne, a fifty-nine-year-old mother of three, the first thing she told me that she missed not being able to feel herself in shoes. Leanne had become bedridden and almost paralysed as the aggressive neoadjuvant combo therapies of chemo and radiation had taken their toll. Too weak and frail, she had been medically re-categorised from 'radical surgery' to 'palliative': her potentially life-saving colon surgery cancelled because the treatment had compromised her health and, it was feared, hastened her death. Leanne was a staunch Catholic. She says that she felt that "God had a purpose for all this". In earlier interviews, Leanne revealed that her firm faith afforded her the strength to "bear (her) cross", as she put it. However, now she says that she is preoccupied mostly in the simple acts of managing her illness and her body. She still closes each interview with "there is a God", but this assertion has become increasingly removed from what she now expresses as the realities and experiences of living with cancer.

Like all of the women undergoing radiation, she had also been 'tattooed' in preparation for her radiation. 'Tattoos' are temporary markings on the skin, calculated and laser mapped, and then sketched out with felt markers on the body so that the radiation beams are precisely aimed during the seven-minute radiation treatments. Many women also vividly recall their naked skin rigidly placed flushed against the cold flat slab that functions as the bed during the radiation treatment. Radiation being administered also meant that the skin around this area could not be washed for the several weeks or months of the treatment. For women with rectal tumours, this presented immense and obvious challenges. 
The treated skin also suffers deep burning and is extremely painful. Lauren, who had radiation to most of her upper body, says:

You take for granted the simple pleasure of water on your skin ... food slipping down painlessly down inside your throat, touching your face ... even feeling the skin of your lips when you talk ... .

Spending time in the oncology waiting rooms and interacting with the women allows one to get a sense of some of the difficulties faced by the women with the most taken-for-granted tasks around very personal issues of self care. Women that a few weeks earlier came in relatively well dressed and with a sense of quiet but discernible eagerness around treatment options, and who seemed to even enjoy meeting other women with whom they could talk and share symptoms, now appeared bowed and visibly smaller. Often too weak to bother with the pleasantries of dress, they arrived in simple gowns: a radically different 'presentation of self' (Goffman 1959) in more ways than one. Many women, who had walked into the daily radiation treatment at the beginning of the prescribed regime, now came to finish the final stages of their course of radiation assisted in wheelchairs and some even on stretchers. Many took on the pained appearance of strangers uncomfortable in their (changed) bodies. One of the elderly mothers had become completely bedridden and was one of those who saw out the last sessions of her second course of radiation with daily hospital visits coming in on a stretcher. Her colorectal cancer had spread to her bone and she had become immobile because the cancer had dangerously eroded three of the cervical vertebrae in her neck. She relied on her family of caregivers and had to be brought to the hospital in the St. John's Ambulance, who offered a transport service at a special discounted rate to oncology patients. From what I could observe, she clung to the one cherished cultural item that she could wear as a married woman: her traditional marriage dot, worn on the skin of the forehead. But during the course of her illness, even as her family prepared for her death, she lost one of her main caregivers, her husband. And as is the custom and culture for Hindu widows, she was no longer able to wear the bottu (or dot). When she died a few months later, her customary funeral rites did not include this cultural marking on the skin.

Perhaps I will be read harshly for only sharing so called 'chaos stories' (Wong and King 2008:58I) of failed treatments and horror symptoms, and be accused of glossing over 'restitution' and 'triumph stories' (ibid). I do not deny that there are women who have experienced their cancer as enlightening and as a 'wake-up call' and who have journeyed to the edge of death and returned in triumphant remission. However, there is, understandably, much less agency for most of the women in this study, who were receiving palliative care and were considered terminally ill. These women had journeyed to the edge of life and the land of the living and now squatted at the borderlands. Even the women who had breast cancer and were in remission, while demonstrating much greater agency, still expressed intense fear that remission was just a reprieve, possibly a mere short probation.

Medical interventions need, on some level, to acknowledge that for cancer patients, as for other terminally ill patients, death and dying are both proximal and disjunctive (embodied) experiences. From what the women shared, dying happens in multiple ways and countless times before death. Some of this can be couched and comprehended within a medicalized framework of organ failure and near fatal side effects of the prescribed treatment and medication regimes. The women in this study described going into cardiac arrest, being temporarily comatose, suffering stroke and seizure, and being in coma (induced by fatal blood sugar levels). However, there were also narratives of levels of dying experienced in palpable emotional terms. The women described feeling 'lifeless' and spoke about a kind of 'disembodiment' after treatments that were supposed to provide relief and possible remission. They also described feeling 'dead' as they relinquished control of their bodies to the medical staff and family care givers. Many of them mentioned that the doctors seemed to "treat the cancer ... not us ..." The complex relationship between death and dying thus emerged many times in the interviews. For example, one woman poignantly said: "I don't mind death; it's the dying that I mind."And at least four others claimed that they were in some ways "dead already", while another said: "I wish it [death] would be merciful and come sooner rather than later." Similarly, yet another elderly mother told me, "don't they, [the doctors] realise that the treatment is not saving me ... it's killing me?"

Death and dying thus emerged as tensions that are both proximal and disjunctive in terms of what they mean to cancer patients. Dying did not necessarily precede death, nor was death necessarily from the process of dying. Rather, as the narratives and women's experiences reveal, they are both part of a series of 'performances' in the imaginary of life, pain and suffering within a shifting landscape of hope and disillusionment, pain and relief. The women's experiences reveal instances when they fervently longed to live and be with their loved ones and to belong to the world of the living, and other moments of where they say they "prayed for death". The yearning to live and the yearning to die were both proximate and disjunctive refrains in the narratives.

And to the women in this study - who were patients and not doctors, the 'hearers' and not the usual 'tellers' in the medical discourse that begins to take shape around the oncologist's consultation - cancer was both semiotically and literally, about both death and dying. It was also both medical and social. To them it was the beginning and the end, in as much it spelled the beginning of the end for many. For a disease that in most instances has come to signify death, it is thus powerfully alive within and on the body of the patient in ways that are at once both visceral and visual. To the physician, death and the process of dying happens to the body in measurable and quantifiable terms, while to the patient, dying-anddeath is what happens to them emotionally through the materiality of the body.

Health and illness are 'phenomena' that are 'material' and 'experiential' (Fox 201 I:359). The narratives in this study give credence to Fox's assertion that while diseases affect organs and cells, they also influence experience and identity. However, his contention is that despite the elaboration of a social model of embodiment, many scholars still saddle themselves with an "implicitly or explicitly biomedicalised body as the location of 'health' and 'illness', and as the ontological unit of 
sociological analysis" (ibid).

\section{Conclusion}

Shilling noted that the body is the "irreducible source of society', the "corporeal basis on which identities and social relations are consolidated and changed" (2003: 210). I believe that one way to understand the ill body and the ill person, within this sociological framework, is through their illness narratives. For the embodiment of cancer patients (or the Self with-cancer-body, as revealed to us in the narratives of the study) is complex and layered and transcends the epidemiological face of the illness. Disease and disorder, functioning and malfunctioning, emerge in and through female bodies marked by illness and by a profound sense of non-belonging. For the women in this study, living with cancer means experiencing docility, powerlessness and alienation (even from their own bodies), while also attempting to preserve power and control, and experiencing pain and suffering that potentially transform the subjective meanings of who they are.

Recent social sciences accounts working within a wider social framework (Twigg 2002, Lee-Treweek 2002, Harrison and Smith 2004, Twigg 2006) have been acutely aware of the limitations of traditional medicine in comprehending, and therefore meaningfully assisting, the experience of the patient. As Twigg reminds us, for many patients, the experience of modern medicine, especially hospital-based and experienced medicine, “... is a disjunctive one, involving not just pain but also dislocation, objectification and a denial of their sense of embodiment" (2006: 98). The inscriptional approach and practices offered by medical treatments, largely underwritten by epidemiological and environmental impact studies, is thus experienced as being territorial and debilitating enough to alter relationships, even the most fundamental relationship, between one's own body and self. We are therefore compelled to become increasingly vigilant of the dominant ideologies of illness and body, through which we are increasingly obliged to enact illness and health.

Poststructural approaches that are cognisant of pluralistic perspectives offer a measure of vigilance as they challenge fundamental canonised positions in social theory and allow a destabilising and re-reading of (contested) central ideas in medical health. Nick Fox (2004; 20I I, 20I2) draws our gaze to the organization (and need for reorganisation) of the "care relationship' as powerful sites for this destabilising. He asks for a re-appraisal of issues of structure, identity and knowl- edge in medical sociology and points out that it has been complicit in the creation of particular constructions of 'the patient' and of 'health' and 'illness' (2012:6) as medical knowledge. Fox's discussion is around developing a perspective for revealing the politics of 'health talk' or 'illness talk' (ibid.), pointing out what is becoming increasingly more obvious: that illness is never merely just illness.

My plea is that, as researchers working on social issues around health, and in our bid for reorganisation of the care relationship and of care models, we need to push for greater recognition of that which may seem deceptively obvious, but which appears to elide the 'medical gaze' of many, that in dealing with 'illness', we are actually dealing with 'ill people'. We need to add to the urgency by proposing a more humanistic ${ }^{6}$ postmodern medical social science that is focused on the creation of models of care (and palliation) through qualitative phenomenological work with patients and the physicality of their illnesses. For me such a perspective allows a privileging of the patients' corporeal body.

I was aware that for many of the women, the yearning to have the corporeal experience of their illness fully understood by the health care practitioners was profound. This however, went far beyond just gaining a measure of therapeutic relief (see Goldstein 2004, Carlick and Biley 2004, Helsinki 2009) ${ }^{7}$ from the 'telling' of their illness, Put simply, they appeared to yearn for a more humane medical care that saw through their illness, to them. To me, this was the deeply embedded significance in their narratives. Qualitative and ethnographic studies that seek to 'collect' their illness narratives have thus a critically vital role to play within the context of the social sciences and within 'narrative medicine'. The medical practitioner, Rita Charon ${ }^{8}$, defines 'narrative medicine' as "clinical practice fortified by narrative competence the capacity to recognize, absorb, metabolize, interpret, and be moved by stories of illness" (Charon 2003). However, just as crucially, narrative medicine is put forward as looking "beyond solely patient-focused narratives" and is claimed as being capable of offering a contribution to wider public health policy through offering a "personalised understanding of medicine" (Dasgupta 2003:243) that is capable of acting as a model for humane and effective medical practice.

Narrative medicine can, in a sense, be seen as possessing 'soft edges' or potentially porous boundaries between the social and medical sciences. Thus, for the last several years there have been voices within clinical medicine putting for-

6. The large Kreuter et al. (2007) study is a product of the US National Cancer Institute's (NCl) interdisciplinary Working Group on Narrative Communication in Cancer Prevention. This paper proposed a typology of narrative application in cancer control that they claimed stimulates critical thinking about the role of narrative in cancer communication. Such studies compel us to acknowledge the importance of narratives in helping to create meaning in people's lives. These kinds of studies, that recognise the human and social face of cancer, make up at least $20 \%$ of the research focus of the $\mathrm{NCl}$ and transcend seeking to understand cancer and the cancer patient merely in terms of a grammar of pathology. Contrastingly, CANSA or The Cancer Association of South Africa has projects spanning 'Type A' to 'Type D'. However, most of the 'Types' of research projects cover epidemiological and environmental carcinogen impact studies, and it is only 'Type C' that looks at projects that "concern the patient-orientated services" such as "palliation of cancer patients". See 'The Cancer Association of South Africa' on http://www.cansa.org.za/

7. In her study of AIDS legends, American folklorist Diane Goldstein pointed out that "the narratives we hear and tell" are capable of challenging "dominant constructions" (Goldstein 2004: 157) around the discourse of illness and health. Carlick and Biley's (2004) study identified a growing awareness of the role that narratives can play in helping cancer patients cope with their illness, while the more recent work by Helsinki (2009) showed how dream narratives function in the context of personal cancer experience, and emphasised the importance of comprehending the wider socio-cultural frameworks applied to particular narrative discourses.

8. Rita Charon is from the Department of Medicine and Program in Narrative Medicine, Columbia University. 
ward the more patient-centred narrative medicine as a methodological teaching approach to understanding 'illness and health' that can be taught to medical students. Satayani Dasgupta who is herself a member of Charon's 'narrative medicine' teaching team at Columbia University, maintains that the health-care professionals potentially most sensitive to the power differentials and oppositions in the patient-doctor dyad, and who are "perhaps most ideally positioned to critique and change them", are medical students, or the "doctors-to-be'(see 2003; 2007). Dasgupta's (2003:24I) point is that these students occupy a unique position, as they are both within the health care system, yet still, in a sense, outsiders. Later, similarly veined research projects (Charon 2006:1265) show evidence that students and clinicians who have undergone narrative training with her have strengthened "their therapeutic alliances with patients". It was Trisha Greenhalgh who reminded us over a decade ago that "appreciating the narrative nature of the illness experience" in essence "does not require us to reject the principles of evidence-based medicine" (1999: 325). She pointed out that such an approach does not necessitate an "inversion" of the established hierarchy of evidence to the extent "that personal anecdote carries more weight in decision making than the randomised controlled trial" (ibid), but, instead, invites the use of an interpretive paradigm through which it is understood that the patient experiences illness in a very particular manner.

Narrative medicine has also been put forward as one solution to an increasingly impersonal medical environment, where educators in the medical humanities ${ }^{9}$, like those on Rita Charon's team, turn to narratives and narrative studies to teach medical students "an emotionally fulfilling and interpersonally related professional practice” (Dasgupta 2007:1384). Such an approach is seen as a way to commit to "fostering the use of the humanities, social sciences, and the arts as a lens for examining issues in health, medicine, and healing". Dasgupta claims that illness narratives written by those suffering illness, form a genre of writing that has grown significantly in the past few decades, adding that such stories, or pathographies (see Aronson 2000), are "a postmodern phenomenon, in which narratives authored by the ill give voice to an experience that was once narrated solely by the medical establishment" (Dasgupta 2007:1386).

Not all patients can be their own 'writers' of suffering. Yet there are others, who can be the 'tellers' or narrators of some of the patients' pain. Perhaps the plea from within the social sciences for a more humanistic medical model of care, can articulate through a qualitative gathering of the illness narratives by researchers. These can, in turn, act as powerful textual sources of pain and suffering that can be read and heard by those who seek to assist with that pain and suffering, as well as assisting in shifting the medical gaze to look through and beyond technological diagnostics, and see the person being diagnosed.

Herein then lies the power of such stories of experiencing illness and yearning for health. Goodfield's observation, made all of thirty seven years ago, is still potently true, and one that needs to be held in sight of the medical gaze: Goodfield asserted that;

Cancer begins and ends with people. In the midst of scientific abstraction, it is sometimes possible to forget this one basic fact. (Goodfield 1975: 219)

\section{References}

Aronson, Jeffrey K. 2000. Group Autopathography: The Patient's Tale. British Medical Journal 32I (7276): I599-1602.

Brown, Patrick R.; Alaszewski I, Andy; Swift, Trish and Nordin, Andy. 201I. Actions speak louder than words: the embodiment of trust by healthcare professionals in gynae-oncology. Sociology of Health \& IIlness 33 (2):280-295.

Butler, Judith. 1993. 'Bodies that Matter', in Feminist Theory and the Body: a Reader. Edited by J. Price and M. Shildrick, pp. 235-245. New York: Routledge.

Carlick, A and Biley, F.C. 2004. Thoughts on the therapeutic use of narrative in the promotion of coping in cancer care. European Journal of Cancer Care 13:308-317.

Charon Rita. 200I. Narrative Medicine: A Model for Empathy, Reflection, Profession, and Trust. JAMA 286 (15): I897-1902.

Charon, Rita. 2005. What to do with stories: The sciences of narrative medicine. Canadian Family Physician - Le Médecin de famille Canadien 53: I265-1 267.

Daiute, C., and Lightfoot, C. 2004. Narrative analysis: Studying the development of individuals in society. Thousand Oaks CA: Sage.

Dale, B. and Altschuler, J. 1999. In sickness and in health: The development of alternative discourses in work with families with parental illness. Journal of Family Therapy 21:267-283.

Dasgupta, Sayantani. 2003. Reading Bodies, Writing Bodies: SelfReflection and Cultural Criticism in a Narrative Medicine Curriculum. Literature and Medicine 22 (2):24I-256.

Dasgupta, Sayantani. 2007. Between Stillness and Story: Lessons of Children's Illness Narratives, Journal of American Academy of Paediatrics II 9 (6): | 384 - I39|.

Denzin, Norman. 1989. The Research Act: Theoretical Introduction to Sociological Research Methods. Englewood Cliffs, NJ: Prentice Hall.

Douglas, Mary. 1970. Purity and Danger. London: Routledge.

Fox, Nicholas J. 2004. Postmodernism, Sociology and Health. Toronto: University of Toronto Press.

Fox, Nick, J. 20I I. The ill-health assemblage: Beyond the body-withorgans Health Sociology Review 20 (4):359-37I.

Fox, Nick J. 2012. The Body. Malden, Mass.: Polity.

Goffman, Erving. 1959. The Presentation of Self in Everyday Life. Garden City, NY: Doubleday Anchor.

Goldstein, Diane E. 2004. Once Upon a Virus: AIDS Legends and Vernacular Risk Perception. Logan: Utah State University Press.

Goodfield, June. 1975. The Siege of Cancer. New York: Random House.

Greenhalgh, Trisha. 1999. Narrative based medicine in an evidence based world. BMJ 318 (7179):323-325.

Harrison, S. and Smith, C. 2004. Trust and moral motivation: redundant resources in health and social care? Policy and Politics 32(3):37I-86.

Helsinki, Piret Paal. 2009. Dreams and Dream-like Imagery in Cancer Patients' Narratives. Fabula 50:273-282.

Herndl, Diane Price. 2006. Our Breasts, Our Selves: Identity, Community, and Ethics in Cancer Autobiographies. Signs 32

9. 'Medical humanities' is defined by the Yale Medical Humanities Council as an interdisciplinary subject that draws on the humanities (literature, philosophy, ethics) as well as the social sciences (anthropology, sociology, psychology) and the arts (theatre, visual arts etc.), and is relevant to the teaching and practice of medicine. And the stated aim of the Yale Medical Humanities Council is "to service the Yale Medical School community. http://medicine.yale.edu/humanities/index.aspx 
(I):22I-245.

Juraskova, I., Butow, P., Robertson, R., Sharpe, L., McLeod, C. and Hacker, N. 2003. Post treatment sexual adjustment following cervical and endometrial cancer: a qualitative insight. PsychoOncology 12 (3):267-79.

Karwalajtys, Tina L., Redwood-Campbell, Lynda J., Fowler, Nancy C., Lohfeld, Lynne H. and Howard, Michelle. 20I0. Conducting qualitative research on cervical cancer screening among diverse groups of immigrant women, Research reflections: challenges and solutions, Canadian Family Physician 56 (4): I 30- I 35.

Knopf-Newman, Marcy Jane. 200I. Poison: Fallout in the Breast Cancer Veteran's Jungle. Pacific Coast Philology 36:8I-I0I.

Kristeva, Julia. 1982. Powers of Horror: An Essay on Abjection. New York: Columbia University Press.

Kreuter, Matthew W.; Green, Melanie C.; Cappella, Joseph N.; Slater, Michael D.; Wise, Meg E.; Storey, Doug; Clark, Eddie M.; O'Keefe, Daniel J.; Erwin, Deborah O.; Holmes, Kathleen M.P.H.; Hinyard, Leslie J.; Houston, M.S.W. Thomas, and Woolley, Sabra. 2007. Narrative Communication in Cancer Prevention and Control: A Framework to Guide Research and Application. Ann Behav Med 33 (3):22 I-235.

Lee-Treweek, G. 2002. Trust in complementary medicine: the case of cranial osteopathy,

Sociological Review, 50(I):48-68.

Markovic, Milica; Manderson Lenore and Quinn, Michael. 2004. Embodied Changes and the Search for Gynecological Cancer Diagnosis Medical Anthropology Quarterly, 18(3):376-396.

Mukherjee, Siddhartha. 2010. The Emporer of all Maladies. New
York: Scribner.

Naidu, Maheshvari. 2009. Glaring invisibility: dressing the body of the female cleaner, Anthropology Southern Africa 32(3\&4):I28138.

National Cancer Institute (NCl) on http://www.cancer.gov/

Petraglia J. 2007. Narrative intervention in behavior and public health. Journal of Health Communication 12:493-505.

Reissman, C. K. 1993. Narrative analysis. Newbury Park, CA: Sage.

Salander Par and Hamberg, Katrina. 2005. Gender Differences in Patients' written narratives about Being Diagnosed with Cancer Psycho-Oncology, 14:684-695.

Shilling, C. The Body and Social Theory (2nd Edition) London: Sage, 2003.

Twigg, J. 2002. The Body in Social Policy: Mapping a Territory. Journal of Social Policy, 3 I (3):42I-439.

Twigg, Julia 2006. The Body in Health and Social Care. Basingstoke: Palgrave Macmillan.

Van der Riet, Pamela. 1998. The sexual embodiment of the cancer patient. Nursing Inquiry 5: 248-257.

Waskul, Dennis D. and van der Riet, Pamela. 2002. The Abject Embodiment of Cancer Patients: Dignity, Selfhood, and the Grotesque Body. Symbolic Interaction 25 (4):487-5 I3.

Wong, Nancy and King, Tracey. 2008. The Cultural Construction of Risk Understandings through Illness Narratives. Journal of Consumer Research 34 (5):579-594.

Yale Medical Humanities Council on http://medicine.yale.edu/ humanities/index.aspx 